\title{
Reivindicaciones urbanas y organización popular. El caso de Durango
}

\author{
Juan Manuel Ramírez Sáiz*
}

De acuerdo con una tesis generalizada hasta mediados de los años setenta, y todavía vigente, las organizaciones de colonos e inquilinos pobres en México creen en la legitimidad de las instituciones del sistema y, en buena parte, las apoyan. Sus demandas se encuentran subordinadas y cooptadas por el Estado y rechazan la vinculación con los partidos de izquierda. En cuanto a los movimientos urbanopopulares independientes, se sostiene actualmente que su número es reducido, constituyendo manifestaciones colectivas de escasa duración, con bajo nivel de politización y sin capacidad de iniciativa ni de formulación de propuestas urbanas alternativas.

A través de un estudio de caso, en este artículo se somete a revisión la versión relativa a los movimientos urbanos populares autónomos, centrándose en el análisis de una organización que surgió en Durango, una ciudad de tamaño medio que posee un bajo índice de industrialización. A partir de 1972 e incorporando las experiencias de movimientos locales anteriores, el Comité de Defensa Popular (CDP) lucha por demandas tanto urbanas como politicas y culturales. El Comité está avanzando en su consolidación interna, ha brindado solidaridad y establecido alianzas con otros grupos independientes de la localidad y está desarrollando una labor importante para unificar las diferentes organizaciones independientes que reivindican demandas similares en el país. Por ello, posee una dinámica propia y una proyección política, constituyendo una de las fuerzas importantes a nivel local, ya que nuclea contingentes similares o mayores que los que integran las organizaciones paralelas del estado en Durango.

El caso estudiado demuestra que la hegemonía del Estado en este terreno es modificable, que las luchas de las mayorías urbanas no deben necesariamente realizarse a través de una relación clientelista, con él y, asimismo que los movimientos urbanos populares independientes están avanzando en su estructuración interna $y$ en sus niveles de politización.

\section{Aspectos teórico-metodológicos}

El grado de desarrollo político de las formaciones sociales se encuentra estrechamente relacionado con la existencia de organizaciones representativas de grupos (partidiarios o no) que operan como interlocutores y mediadores entre la sociedad civil y el Estado. En las sociedades contemporáneas, los movimientos sociales de distinto tipo constituyen un fenómeno que está adquiriendo fuerza creciente en cuanto expresión de chimilco.

* Profesor-investigador de la Universidad Autónoma Metropolitana, Xo- 
problemas nuevos (ecológicos, culturales, de transporte urbano, feministas, municipales, etc.), que emergen en el panorama económico y político y se convierten en factor aglutinante de sectores que actúan como portavoces de ellos. Estas prácticas sociales colectivas son llevadas a cabo por grupos organizados (formal o informalmente) para defender sus intereses, reivindicar sus derechos y lograr la atención de sus necesidades y demandas. Estos comportamientos se están registrando, de manera creciente, no sólo en las sociedades capitalistas avanzadas sino también en las periféricas y dependientes (Castells, 1974 y 1981).

El nivel de la teorización sobre este campo de la acción social es todavía incipiente en la sociología tanto de inspiración funcionalista como en la de orientación marxista. Al respecto, los análisis de la primera (en particular de N.J. Smelser y Ch. Tilly) giran en torno a la activación de los factores de la acción colectiva (collective behavior); dicha aproximación asume a las creencias de los actores como la clave de explicación de las conductas colectivas, a las que interpreta como tensiones que disturban el supuesto equilibrio del sistema social. Sobre la violencia, las revueltas, etc., han aportado abundantes bases empíricas, pero sin precisar las condiciones objetivas que las hacen posibles y relegando el análisis de sus implicaciones políticas (Melucci, 1982:84). En el caso de los diferentes aportes marxistas, se enfatizan las contradicciones del sistema capitalista como causas de los conflictos sociales, ignorando los procesos de formación de las acciones colectivas y su relación con el sistema de dominación; por ello este tipo de estudios "devalúa y excluye del análisis todas las formas de acción que no se dejan reducir al modelo del partido (político)"' (Melucci, 1982:85) y no explica cómo se pasa del análisis de las relaciones de clase a una definición de la acción de clase y después a una acción política. Y tanto en el caso del funcionalismo como en el del marxismo, la reflexión teórica carece todavía de categorías e instrumentos de análisis para abordar y explicar con rigor estas nuevas formas de acción social. Los llamados "movimientos sociales urbanos" son quizá una de las más conocidas de ellas. En los trabajos relativos a América Latina predominan los estudios centrados en las demandas organizadas a nivel del barrio en cuanto unidad espacial y social; buena parte de ellos han sido realizados por investigadores norteamericanos, y Wayne A. Cornelius (1974) ha resumido sus conclusiones centrales. Otra vertiente teórica que ha impulsado el estudio de este fenómeno en los países de habla hispana es el grupo de sociólogos marxistas influenciados por A. Touraine, en particular M. Castells y J. Borja. Esta doble influencia teórica existe también en los estudios sobre los "movimientos sociales urbanos" en México. En los trabajos efectuados hasta mediados de los años setenta predominan el análisis sobre colonias y movimientos populares vinculados al sistema y el enfoque teórico de la sociología funcionalista. El mejor exponente de este tipo de abordaje es el del ya citado W.A. Cornelius y su 
obra Los inmigrantes pobres en la ciudad de México y la política. Este autor precisa que sus estudios "no reflejan los cambios que hayan ocurrido en el periodo después de 1972" (Cornelius, 1980:9). Aunque por la muestra de colonias seleccionada y el lapso acotado no pudo incluir el fenómeno del movimiento urbano popular independiente, su aclaración es oportuna, pues si bien el hecho se inicia con anterioridad (sin considerar el movimiento inquilinario de los años veinte), es en la década de los setenta cuando se pone en marcha un proceso de organización y movilización de colonos, inquilinos, posesionarios y solicitantes de tierra y vivienda que actúan con independencia del Estado y su partido. La hegemonía del PRI y sus instancias para la integración y control de las masas urbanas (CNOP, etc.) se mantiene, pero va acusando una pérdida relativa. Y grupos crecientes de habitantes pobres de las ciudades rechazan la relación clientelista y de supeditación con el sistema. La exploración y estudio de este fenómeno en el país se realiza bajo la influencia del citado grupo de sociólogos marxistas. Pero tanto como resultado del análisis de las características específicas de estos movimientos autónomos en México como de la revisión del contexto teórico-político pluriclasista de dicho grupo, se introdujeron dos elementos fundamentales para su abordaje: su carácter popular o proletario en sentido amplio y su aporte a la lucha política independiente. En lo relativo al primer aspecto, conviene recordar que bajo la categoría de "movimiento social urbano" suelen englobarse prácticas colectivas que corresponden a distintas clases sociales; por ello, este término ha sido sustituido en México por el de movimiento urbano popular (MUP) o independiente. Aunque este concepto ha sido propuesto y es utilizado por sus protagonistas, la realidad subyacente exige ser precisada con mayor rigor, pues si bien es cierto que el término popular permite distinguir a este agente social de otros movimientos urbanos integrados por capas medias o por la burguesía, no acota su especificidad porque el movimiento obrero o el campesino son igualmente populares y asimismo las organizaciones de colonos e inquilinos cooptados por el Estado. Tampoco el calificativo de independiente define, por sí mismo, a estas prácticas sociales, porque es común a las agrupaciones sindicales y campesinas que actúan con autonomía de las organizaciones de masas del partido oficial. Y la caracterización de urbanos es demasiado amplia en sociedades progresivamente industriales y que concentran la mayor parte de sus actividades y población en las ciudades. La combinación de varios calificativos (urbano-popular) disminuye estas imprecisiones pero no las elimina. En realidad, la especificidad de este movimiento viene dada por sus integrantes y el tipo de demandas que levantan. A partir de ambos elementos, sería más correcto denominarlo como movimiento de colonos, inquilinos, solicitantes, etc., o luchas por el suelo urbano, la vivienda, los servicios, etc., aclarando, en cada caso, su posición política y relación con el Estado (supeditación o autonomía). Por ello, los tér- 
minos MUP o movimiento independiente no son incorporados en este trabajo como categorías acabadas, sino en tanto reflejan el nivel de los estudios que, hasta el presente, se ha logrado en este campo de la investigación urbana. En relación a las demandas planteadas, conviene recordar que el "movimiento urbano popular" reivindica derechos básicos relacionados con la reproducción de la fuerza de trabajo (tanto en activo como del ejército industrial de reserva) en las ciudades mediante mejores condiciones materiales de vida en sus lugares de residencia; lucha asimismo por el reconocimiento autónomo de sus organizaciones por parte del Estado y de las restantes instancias de la sociedad civil; demanda igualmente el respeto y ejercicio de sus derechos democráticos y políticos y, de manera creciente, exige la participación en la toma de decisiones relacionadas con su hábitat. En el surgimiento de este actor social están implicados factores tanto económicos como políticos; entre ellos, se enfatiza, así sea esquemáticamente, de acuerdo con los resultados de investigaciones de otros autores y de trabajos personales (Topalov, 1975; Copevi, 1977; Casanova, 1984; Ramírez, 1983, 1986 y 1986b), los siguientes:

1. La producción capitalista de vivienda constituye para los agentes económicos que intervienen en ella (terratenientes, constructores, promotores inmobiliarios, financieros, etc.) una mercancía más de la cual extraer plusvalía y no tanto un medio para satisfacer necesidades de la población.

2. El enorme contingente de desempleados y subempleados existente en las ciudades (como resultado de las migraciones y de la escasa generación de fuentes de trabajo), así como la insuficiencia del salario para cubrir las necesidades básicas de la reproducción de la fuerza de trabajo, provocan que sus condiciones materiales de vida presenten niveles graves de deterioro.

3. Un buen número de contratos colectivos de trabajo no incluyen cláusulas relativas a prestaciones relacionadas con la situación de habitantes de la ciudad que caracteriza a los trabajadores urbanos (acceso a la tierra, dotación de servicios urbanos, contaminación ambiental, etcétera).

4. Los programas y, sobre todo, la actividad de los partidos políticos de oposición se hallan, en gran parte, desvinculados de las reivindicaciones urbanas de los ciudadanos.

El gobierno y su partido han percibido, desde hace tiempo, lo conflictivo de esta compleja realidad y su potencialidad política y, por ello, la han controlado y capitalizado sus posibilidades. Pero la mediatización y neutralización que han ejercido tanto de la problemática urbana como de las mayorías que la padecen motivó que un número cada vez mayor de colonias y movimientos se opongan a la relación de cliente que implica.

En el nacimiento autónomo o distanciamiento del Estado por parte de los movimientos urbano-populares intervienen varios elementos aún no suficientemente analizados; entre ellos destacan: a) las divisiones in- 
ternas del partido en el poder, de carácter coyuntural; b) las pugnas transitorias que pueden darse entre el partido oficial y las fracciones dominantes de la burguesía; c) el distanciamiento, retiro temporal de apoyo a los conflictos pasajeros entre el poder central y los estatales; d) los periodos de apertura democrática o "populismo", especialmente por parte de las autoridades centrales; e) la presencia en las colonias populares de activistas y militantes, provenientes del movimiento estudiantil, de comunidades cristianas de base y de corrientes políticas y nuevos partidos de izquierda, que logran identificarse con los intereses de los MUP y son incorporados como tales por ellos, y f) la progresiva formación de cuadros y dirigentes al interior de los MUP, que van rompiendo las estructuras caudillistas y apoyando la participación de las bases.

En lo que se refiere a la aportación de los "movimientos urbanos populares" a la actividad política independiente, tanto en los análisis de teóricos sociales ${ }^{1}$ como en las apreciaciones de organizaciones políticas ${ }^{2}$ afloran una serie de afirmaciones que implican una concepción reduccionista de los mismos. Su explicitación gira en torno a un conjunto de supuestos cuyos ejes centrales son los siguientes: a) dichos movimientos asumen la forma de manifestaciones espontáneas y masivas que surgen a raíz de alguna demanda o conflicto y que, una vez resueltos, provocan la desarticulación y desaparición de las organizaciones; b) en general, se encuentran aislados respecto de movimientos similares y de organizaciones políticas (partidos y corrientes); c) su nivel de politización es muy bajo, es decir, luchan fundamentalmente por reivindicaciones economicistas;

${ }^{1}$ E. Pradilla sostiene: “Comúnmente observamos en América Latina que los asentamientos proletarios o de otras capas explotadas que han logrado cierto nivel de consolidación y equipamiento presentan mucha menor tendencia a movilizarse en términos de las reivindicaciones materiales propias, y que las colonias o los movimientos que fueron más dinámicos, más combativos en el pasado, obtenidas las reivindicaciones básicas, tienden a irse desmovilizando, a aquietarse y a participar cada vez menos en la lucha en su conjunto" (Pradilla, s.f.: 2).

A. Sánchez-León afirma: "La población -como suele ocurrir en su lucha por los servicios - una vez solucionado el problema (de la tierra), vuelve a asumir actitudes individuales o parciales. Los avances en la conciencia de los pobladores y las movilizaciones de masas están sujetas a coyunturas y a reivindicaciones precisas. Una vez que el objetivo ha sido alcanzado o se han superado los momentos mas difíciles, el ánimo y la movilización desciende, así como el interés por asumir luchas de carácter político" (Sánchez-León, 1983: 55).

F. Zapata afirma: (los movimientos) "no alcanzan una dinámica que permita contrarrestar la reacción estatal y son frecuentemente reprimidos sin que sea posible su supervivencia en el mediano o largo plazo. El impacto de la acción de dichos movimientos es pasajero y constituye un impacto puntual que no tiene secuelas en el acontecer histórico del país. . . No es fácil encontrar vínculos entre campesinos, pobladores y obreros y menos todavía entre éstos y las clases medias"' (Zapata, 1985: 12 y 14).

2 El PSUM afirma: "La ideología del movimiento popular urbano está fuertemente controlada por el aparato gubernamental" (PSUM, 1982:8). 
d) en su mayoría, están integrados a la política oficial; los escasos que se mantienen independientes respecto de ella disponen de contingentes minoritarios en relación con las organizaciones paralelas del Estado, y e) su actuación es más un reflejo de o una respuesta a diferentes intervenciones del Estado que el resultado de iniciativas propias.

En conjunto, estos juicios aluden a una realidad compleja y que, por ser presentada en sus elementos esquemáticos, logra su fácil aceptación. Sin embargo, actualmente se dispone ya de trabajos de carácter global y de estudios de caso, los cuales permiten matizar $\mathrm{y}$, en algunos aspectos invalidar, los asertos anteriores (Alvarado, 1982; Moctezuma, 1981; Mercado, 1983; Ramírez, 1986). A través de ellos han logrado cierta difusión movimientos como el inquilinario de Veracruz de los años veinte y otros de la década de los setenta como la colonia Rubén Jaramillo de Cuernavaca, la colonia Francisco Villa de Chihuahua, el Frente Popular Tierra y Libertad de Monterrey, y el Campamento 2 de Octubre y San Miguel Teotongo en el D.F., el Movimiento Restaurador de Colonos de Netzahualcóyotl en el Estado de México y el Consejo General de Colonias Populares de Acapulco. Los casos aludidos corresponden a MUP con niveles diferentes de consolidación interna y formas distintas y hasta opuestas de relación con el Estado. Así, el Movimiento Restaurador de Colonos confirma el poder de que dispone el sistema para penetrar, dividir e incorporar a estos movimientos, si no existen mecanismos internos para que los líderes representen y defiendan los intereses reales de sus integrantes. Por su parte, la breve vida de la colonia Rubén Jaramillo demuestra la inviabilidad de los MUP cuando ignoran el contexto sociopolítico del país y asumen posiciones radicales que provocan su autodestrucción. El Campamento 2 de Octubre evidencia los riesgos que para la vida de un movimiento autónomo implica depender de un líder, si las acciones que emprende y las alianzas que establece no han sido objeto de discusión amplia y acuerdos por parte de las bases. En cuanto a la colonia Francisco Villa, ella fue inicialmente un foco de integración local de diferentes fuerzas independientes y, en su etapa más reciente, ha participado en contiendas electorales estableciendo alianzas con partidos de diferente orientación ideológica. El caso del Consejo General de Colonias Populares de Acapulco demuestra que la capacidad de movilización y formulación de propuestas alternativas a los planes urbanos del Estado por parte de los MUP se enfrenta a obstáculos difícilmente superables si las medidas puestas en marcha por las autoridades locales cuentan con el respaldo de los poderes centrales. En lo que se refiere a la experiencia del Frente Popular Tierra y Libertad, ella señala la conveniencia de adecuar las tácticas de lucha al modificarse la coyuntura y la correlación de fuerzas locales y, en particular, si se aplican medidas que tienen por objeto directo desarticular al movimiento (Plan “Tierra Propia"). Finalmente, San Miguel Teotongo es un ejemplo del proceso de automatización y evolución políticas de los MUP, con base en la 
participación creciente de los integrantes en el análisis de los problemas internos y en la toma de decisiones. En conjunto, y a pesar de sus diferencias, estos casos demuestran que la tesis generalizada sobre las organizaciones de colonos e inquilinos en el sentido de que aceptan las instituciones del sistema y los planes urbanos del Estado y de que no manifiestan posiciones políticas independientes exige ser matizada y, en lo que se refiere a los MUP, cuestionada en gran parte.

Evidentemente, los "movimientos urbanos populares" que han tenido lugar en el país no se reducen a los enumerados. Ello indica que existe un vasto campo de investigación para recuperar su historia, analizar su estructura y precisar las distintas situaciones por las que atraviesan en cuanto a su grado de consolidación y nivel de politización. $\mathrm{Al}$ respecto, este artículo se concentra en una localidad (ciudad de Durango) y en una experiencia escasamente divulgada (el Comité de Defensa Popular, CDP) cuyas respectivas características no corresponden a la versión dominante sobre los MUP. Las hipótesis centrales en el análisis de este caso son:

1. La existencia de los MUP tiene relación con el grado de desarrollo industrial y urbano de las ciudades, así como con las condiciones materiales de vida de sus integrantes, pero en su surgimiento y consolidación la variable política (tanto a nivel local como interna al movimiento) puede ser determinante.

2. Los MUP más estructurados pueden plantear además de las demandas sectoriales económicas otras de carácter político e ideológico, así como mantener su organización, a pesar de los logros o fracasos que enfrente, e igualmente establecer alianzas con otras fuerzas locales o nacionales.

3. El número de movimientos urbanos cooptados por el Estado es superior a los independientes pero, en determinadas coyunturas y contextos locales, esta relación puede ser modificada.

4. En los movimientos independientes más consolidados, su actuación y dinámica responden tanto a las intervenciones del Estado sobre los colonos como a las iniciativas de éstos como parte organizada de la sociedad civil.

La investigación sobre la pertinencia de estas hipótesis se realizó tanto a través de la entrevista y la observación participante como mediante el análisis de fuentes documentales primarias y secundarias a partir de las cuales se pudiera contextualizar e interpretar la información obtenida por la vía de las técnicas aludidas. ${ }^{3}$

${ }^{3}$ En octubre de 1982 entrevisté a dos dirigentes, cinco cuadros medios y cinco miembros de la base de este movimiento. Tanto los dirigentes como los cuadros y las bases pertenecían a diferentes colonias. Las entrevistas se realizaban de acuerdo con una guía detallada que fue elaborada conjuntamente por Pedro Moctezuma, Juan Manuel Ramírez Saiz y Sergio Tamayo, y aplicada por cada uno a sendas investigaciones. La observación participante se llevó a cabo en la visita a cada una de las colonias del CDP, en reuniones de sus bases, en una sesión de formación de 


\section{El municipio y la ciudad de Durango: contexto económico, urbano y político ${ }^{4}$}

Los análisis sobre los movimientos sociales suelen privilegiar las condiciones objetivas del espacio social en que éstos se desenvuelven como causas de su surgimiento y evolución. Los datos más relevantes sobre la economía y la población del municipio, así como sobre las características urbanas de la ciudad capital de Durango, manifiestan que sus niveles de industrialización son inferiores a la media nacional, e igualmente su grado de urbanización. Así, en la economía del municipio de Durango predominan las actividades terciarias sobre las del sector primario y también en relación con las del secundario. En términos de la PEA, los porcentajes respectivos en 1980 eran: $56.1 \%$, 92\% y $26.5 \%$. Si bien en el último decenio se ha impulsado la actividad industrial en la capital del estado, los mayores índices se registran en Gómez Palacio, ciudad integrante de la región lagunera.

La ciudad de Durango es una localidad de tamaño medio que concentra $80 \%$ de la población municipal. En 1980 contaba con 374882 habitantes; $42 \%$ de la PEA percibía una vez el salario mínimo y $28 \%$ entre una y dos veces dicho salario. La población sin empleo estable es elevada.

Desde el punto de vista urbano se dan en la capital contradicciones y carencias. En relación con los requerimientos del suelo resaltan los correspondientes a vivienda ( 136 ha en 1982), siguiéndole, en importancia, los de servicios y vialidad (103 ha). La oferta pública de tierra es muy limitada para los sectores de menor capacidad adquisitiva, y existe venta ilegal e invasión de tierra privada y ejidal. Las invasiones fueron iniciadas en los años sesenta por líderes del PRI y se agudizaron en el decenio siguiente. Del total de viviendas existentes en la ciudad en 1980 (36 682), $59.96 \%$ no eran aceptables de acuerdo con la calidad de sus componentes. Sin embargo, en las fuentes locales se estimaba que el déficit era en 1982 de 3009 unidades. La oferta habitacional del estado para los sectores de bajos ingresos no alcanza porcentajes significativos, y la vivienda autoconstruida representa los mayores índices. Respecto a la infraestructura y los servicios básicos, en 1982 se estimaba que 30024 habitantes de la capital no disponían de agua potable ni drenaje. En cuanto al renglón educativo, los mayores déficit de aulas se registran en el nivel pri-

cuadros o activistas y presenciando una negociación entre dirigentes y funcionarios del municipio de Durango.

Las fuentes documentales consultadas se detallan en la bibliografía. De la prensa local se revisaron las noticias y comentarios que sobre el CDP aparecieron en los periódicos El Sol de México, La Voz de Durango, Norte y Meridiano durante 1982.

${ }^{4} \mathrm{La}$ información correspondiente a este inciso ha sido tomada de Borrego, 1984; Escudero, 1984; IEPES, 1970 y 1981; Infonavit, 1981; Pizarro, 1983; SAHOP, 1979, a, b, 1982. 
mario y secundario ( 260 y 47 respectivamente). En lo que se refiere a los servicios de salud, en 1979 únicamente $16 \%$ de la población capitalina era atendida en los consultorios disponibles. Estas carencias urbanas son más notorias en las colonias populares periféricas.

De acuerdo con los datos anteriores es importante resaltar que las condiciones objetivas de la ciudad de Durango no son muy diferentes a las de otras ciudades medias y grandes en las que no han surgido movilizaciones populares independientes. Su explicación no debe buscarse tanto en el nivel económico o en el contexto urbano, sino en la variable política. Al respecto, en la estructura de clases del estado de Durango destaca la fracción tradicional de la burguesía, cuyas fuentes principales de extracción de plusvalía u obtención de ganancia son la agricultura, el comercio y las actividades vinculadas con la especulación de la tierra rural y urbana. La fracción modernizante está interesada en la industrialización y tiene su sede principal en Gómez Palacio, pero sus intereses están representados parcialmente por la burocracia política que también desea el desarrollo de las actividades secundarias en la ciudad capital. La fracción tradicional venía aceptando la política corporativa del PRI; sin embargo, debido a la escasa capacidad de renovación demostrada por este partido y a la utilización política que de la crisis y la corrupción de los funcionarios está realizando el PAN, ha manifestado distanciamiento respecto del partido oficial. Por otra parte, si bien los intereses de los industriales se hallan protegidos por el gobierno local y por el PRI, no encuentran (al igual que en otras ciudades del país) en este partido los mecanismos de representatividad interna. Ambas posturas se han visto apoyadas por el alto clero, cuyos intereses económicos se relacionan con la propiedad de los bienes inmuebles que detentan, en particular en la ciudad de Durango, y que encuentran en las posiciones políticas del PAN un margen de maniobra.

Por su parte, las clases populares urbanas han externado, desde los años sesenta, su inconformidad y descontento en las ciudades de Durango y Gómez Palacio. El rechazo a la política del Estado se ha centrado en torno a la protesta contra la política económica y urbana del gobierno local. Las fuerzas más activas han sido los estudiantes y colonos, respaldados por las asociaciones de padres de familia, corrientes sindicales (electricistas y ferrocarrileros) y pequeños sindicatos (tahoneros, etc.) y, coyunturalmente, por los mineros y choferes de la CTM y dirigentes de partidos de oposición.

La insatisfacción de la burguesía y la protesta popular llevaron a la desaparición de los poderes en la entidad en 1966, y posteriormente (1968) al serio cuestionamiento de la política del siguiente gobernador; en la década de los ochenta, el descontento se manifestó en el abstencionismo y en la votación a favor del PAN que llevó a este partido a lograr la alcaldía de la ciudad capital, una diputación federal y otras locales en las elecciones de 1983. Este abance electoral del PAN se ha visto favorecido además 
por la incapacidad del PRI para postular candidatos con arraigo popular, lo que ha disminuido su poder de movilización.

Por lo anterior, es claro que la falta de representatividad que las organizaciones del PRI manifiestan para las fracciones tradicionales y modernizantes de la burguesía local, así como la inconformidad y capacidad de lucha por parte de las clases populares, han creado un clima político difícil para el gobierno y su partido.

\section{Antecedentes del Comité de Defensa Popular (CDP) ${ }^{5}$}

El desarrollo del CDP debe ser ubicado en el contexto de varios movimientos pluriclasistas y otros de carácter propiamente urbano-popular que han surgido en Durango. Su historia se remonta a 1966, cuando nació el Frente Civil Durangueño, un movimiento apoyado por amplios sectores tanto del campo como de la ciudad y dirigido por la fracción de la burguesía explotadora de los bosques de la región. El movimiento reivindicaba que el mineral de hierro que se extraía del Cerro del Mercado, que se encuentra en la periferia de la ciudad, no se exportara a otras entidades (Nuevo León, etc.), sino que se procesara en Durango y que, para ello, se construyeran plantas siderúrgicas. A pesar de la intensa movilización desplegada, prevalecieron los intereses de Fundidora de Fierro y Acero de Monterrey, y el movimiento no alcanzó sus objetivos. Esta misma bandera de lucha fue levantada en 1970 por el Frente Popular de Lucha, también de carácter pluriclasista, con idéntico desenlace, lo que causó desmovilización y alejamiento de la actividad política por parte de la población. El movimiento se dispersó y sus dirigentes se replegaron hacia las zonas campesinas del estado, tratando de impulsar organizaciones que no llegaron a consolidarse. Los contactos que mantuvieron los dirigentes del movimiento fracasado con las vecindades y colonias de la ciudad fueron muy reducidos; éstos se incrementaron en 1972 cuando se detectó el descontento existente a causa del aumento que se pretendía aplicar a las tarifas de agua potable. Con este motivo, tres líderes que habían participado en el movimiento estudiantil de 1968 en la ciudad de México y en las luchas del Cerro del Mercado en 1970 promovieron entre los habitantes de las vecindades la creación de colonias para evitar el pago de las altas rentas. Debido a que el problema más sentido por la población era el de las tarifas del agua, cambiaron su táctica e impulsaron la organización contra la elevación de las tarifas. La respuesta de los afectados fue muy reducida; después de una larga labor de concientización, organización y propaganda, se crearon comités de barrio y vecindad aglutinados en torno a dirigent ss naturales y, a partir de ellos, se constituyó la Unión

${ }^{5}$ La información contenida en este inciso ha sido incorporada principalmente de Borrego, 1984 y Escudero, 1984. 
Popular Independiente (UPI) en agosto de 1972. La UPI recibió el apoyo de estudiantes de la Universidad del estado y de otros activistas que participaron en las luchas del Cerro del Mercado y después de varias movilizaciones, presiones y negociaciones con las autoridades municipales, consiguió que las tarifas de agua se fijaran en los términos que la Unión había formulado en su pliego petitorio. Este triunfo sirvió para que la UPI activara otras luchas, principalmente las de tierra para vivienda a favor de las mayorías de la ciudad. Los diferentes intentos emprendidos se anulaban ante el monopolio del suelo existente en manos de un reducido número de terratenientes; ello condicionó a que los trabajadores contaran como única salida, para obtener vivienda, la invasión de tierra. La UPI utilizó este recurso en varias ocasiones, pero los ocupantes fueron reprimidos y desalojados de los terrenos por la fuerza militar. La experiencia reportó, sin embargo, un aprendizaje importante para la Unión, y en 1973 logró fundar la primera colonia popular de Durango: la División del Norte, que fue objeto de amenazas e infiltraciones por parte del gobierno de la entidad. La necesidad de mantener esta base de acción obligó a concentrar los esfuerzos en esta colonia, dificultando la obtención de nuevos terrenos. Ésta se reanudó en 1976, fecha en que se crean las colonias Emiliano Zapata y Lucio Cabañas. Las autoridades de la entidad desataron una ofensiva contra la UPI y sus colonias, lo cual trajo como consecuencia un repliegue del movimiento. Como respuesta, las colonias creadas intentaron unificar las fuerzas sociales existentes, proyecto que no se materializó sino hasta 1979.

Un balance de este periodo muestra lo siguiente: a) por su composición pluriclasista y por la dirección ejercida por el grupo interesado en la explotación de los bosques de la región, la experiencia del Frente Cívico Durangueño y del Frente Popular de Lucha evidenció que no bastaba contar con un objetivo común a las distintas clases para que un movimiento avanzase y obtuviese resultados para las mayorías. Hacía falta, además, unạ definición precisa de los intereses en juego y un proyecto político claro. La caída del gobernador en el primer caso, y las fuertes presiones ejercidas contra el gobernador siguiente en el segundo, no reportaron ventajas a las clases urbanas mayoritarias; b) a diferencia de los dos casos citados, los siete años de experiencia de la UPI demostraron que las luchas de inquilinos y colonos (aunque no cristalizaron en logros notorios ni inmediatos) permitían, por un lado, iniciar la organización de las clases populares. Por otro lado, impulsaban la movilización independiente ante el sector urbano popular de la CNOP del PRI. Además, daban margen a la búsqueda de alternativas para la reproducción de la fuerza de trabajo en la ciudad sin supeditarse al control del Estado y su partido. Los escasos contactos habidos entre colonos, inquilinos, estudiantes y trabajadores implicaban, además, ir rompiendo el aislamiento entre las distintas reivindicaciones sectoriales. 


\section{La consolidación de una lucha popular: el Comité de Defensa Popular (CDP) General Francisco Villa}

Un descontento generalizado entre la población contra la Comisión Federal de Electricidad (CFE), ocasionado por los altos cobros de las tarifas de luz, fue el motivo de una nueva movilización de las colonias populares de la capital del estado. Éstas se articularon con otras organizaciones autónomas asumiendo la forma de un frente o unión de lucha. El 24 de agosto de 1979 quedó constituido el Comité de Defensa Popular (CDP), que cuenta con 24 bases. ${ }^{6}$ Está compuesto por: a) colonias populares integradas en su totalidad al frente; b) comités populares o grupos existentes al interior de colonias formadas antes de la creación del CDP y que no están afiliadas al Comité; c) varios ejidos y comunidades campesinas; d) un pueblo periférico con características urbanas y, e) la unión independiente de comerciantes y transportistas. ${ }^{7}$ Por lo anterior, es claro que el CDP tiene una estructura de frente amplio. En cuanto a sus sectores integrantes, la participación de campesinos en este frente se debe, por una parte, a los vínculos (ya aludidos) que los dirigentes del movimiento del Cerro del Mercado establecieron con ellos. Esta misma razón explica la presencia de algunos grupos de ferrocarrileros y de estudiantes. En cuanto a la participación de comerciantes y transportistas (además de las razones ya referidas) existe

${ }^{6} \mathrm{El}$ dato corresponde a octubre de 1982. Posteriormente, C. Ganza, corresponsal del periódico Uno más Uno en Durango ha informado que el CDP integra "más de 30 colonias" (19-IX-1984 y 13, 15 y 19-I-1985). Esta nueva cifra no ha podido ser confirmada. Por su parte A. Mercado alude a 19 colonias populares y siete pueblos de otros tantos ejidos (Uno más Uno, 25-viII-1981).

${ }^{7}$ En la composición del Comité se consideran dos aspectos o niveles distintos: a) el tipo de organizaciones que lo integran: urbanas (y, dentro de éstas, sus variantes: de colonos, solicitantes, etc.), campesinas, etc., y b) la ocupación de sus integrantes, en particular de los residentes en las colonias del CDP.

Las colonias más importantes del CDP son: Emiliano Zapata Lucio Cabañas, Tierra y Libertad, José Revueltas, Arturo Gamiz y Genaro Vázquez Rojas. Los comités populares son núcleos organizados al interior de colonias ya consolidadas y en las que el CDP no tuvo influencia en su surgimiento. Estos comités existen en las colonias: Villa Guadalupe, Benjamín Méndez, Valle del Sur, Benito Juárez, IV Centenario, Hipódromo, J. Gpe. Rodríguez, Francisco Zarco, Santa Fe, Maderera, Azteca, Francisco Villa y El Milagro.

Los grupos campesinos afiliados al CDP se ubican en Paso Real, Refugio, Lauro del Villar y Potosí, de los municipios de Poanas y Nombre de Dios.

En la "Unión de transportistas" del CDP, están toleradas las rutas de transporte de carga pero no la de pasajeros.

Las colonias se asentaron sobre tierras con diferentes tipos de tenencia; por ejemplo la Emiliano Zapata y Genaro Vázquez eran de origen ejidal; la Lucio Cabañas pertenecía a pequeños propietarios; la Arturo Sáinz, José Revueltas y Tierra y Libertad a terratenientes. La ocupación de las colonias se hizo tanto por compra como por invasión. 
un fenómeno que ya ha sido analizado en otros países de América Latina y que se detecta igualmente en algunas ciudades de México (Ciudad Juárez, Chihuahua, Monterrey, Durango, D.F., etc.): el fenómeno de la "marginalidad popular" como escenario constitutivo de nuevos actores sociales y de actividades económicas "informales" (Hardy, 1985; Peattie, 1979). En el caso de Durango, los choferes de taxis y de transporte público de carga y los comerciantes (ambulantes y establecidos) generaron sus propias fuentes de empleo, se organizaron independientemente y establecieron vínculos con el CDP para lograr cobertura hacia sus actividades y reforzar su organización. Manteniendo lo anterior, es obligado también reconocer que aunque el CDP tiene una composición de frente amplio, el sector predominante es el de colonos y solicitantes de tierra y vivienda. La estructura de frente amplio existe también en otros MUP como el Frente Popular Tierra y Libertad (FT y L) de Monterrey y el CDP de Chihuahua y, en otras ciudades se ha logrado la unión de algunas colonias independientes antes de que se creara la Coordinadora Nacional del Movimiento Urbano Popular (Conamup) como el CGCP de Acapulco, la Unión de Colonias Populares (UCP) del valle de México y el Frente Independiente de Colonias (FIC) de Sinaloa o, con posterioridad a la constitución de dicha coordinadora, el Comité Unión de Colonos Urbanos de Tijuana A.C. (CUCUTAC), etcétera.

Desde el punto de vista de la ocupación, entre las 9000 familias que integran el CDP predominan los obreros de la construcción, siguiéndoles los empleados de servicios, los obreros de la industria maderera y pequeños comerciantes y, en último lugar, los artesanos. ${ }^{8}$ Esta composición socioeconómica (pluriclasista de clases subalternas) evidencia que, debido a la inestabilidad laboral entre los empleados de la construcción y el autoempleo de los pequeños comerciantes y artesanos, para la mayoría de los habitantes de las colonias del CDP existe la imposibilidad práctica de cubrir sus necesidades, vinculadas con sus condiciones materiales de vida urbana, por medio de la relación laboral o de las reivindicaciones sindicales. Ésta es, por contrapartida, una de las bases objetivas que explica las reivindicaciones urbanas. Sin embargo, el nivel de subempleo o desempleo de los integrantes del CDP no difiere significativamente del existente en otras colonias populares que no han logrado movilizarse para satisfacer sus necesidades de consumo urbano o lo han hecho estableciendo una relación de cliente con el Estado. La particularidad del CDP se detecta al considerar algunos de los elementos estructurales que definen los movimientos sociales, a saber: a) las demandas que plantea; b) su estructura y organización interna; c) las formas de lucha utilizadas; d) los resultados obtenidos; e) su relación con el Estado; f) su articulación

${ }^{8}$ Datos proporcionados en la entrevista a dirigentes; la composición familiar en las colonias populares de Durango es de seis a siete miembros por familia. 
con otras fuerzas sociales, y g) la dimensión social y política de sus luchas.

\subsection{Las demandas del movimiento}

Las reivindicaciones fundamentales de este frente son de carácter urbano: tierra, vivienda y servicios (agua, drenaje, energía eléctrica, pavimentación, educación, servicio médico y, en menor grado, transporte). Las demandas incluyen no sólo la dotación o instalación de servicios sino también las tarifas por el suministro o uso de los mismos en condiciones favorables a las colonias, así como los materiales para la autoconstrucción de las viviendas a bajo precio. Como en la mayoría de los "movimientos urbano-populares", estas demandas son las más sentidas por la población mayoritaria y el CDP las ha convertido en banderas de lucha. A estas demandas económicas iniciales, las colonias del CDP, a medida que aumenta su conciencia política, están agregando otras de carácter político e ideológico. Ellas son, por ejemplo, el reconocimiento, por parte del Estado, de la organización, las libertades democráticas de manifestación y expresión, y el acceso a los medios de comunicación (televisión, radio, periódicos), a fin de impulsar tanto la expresión de los sectores populares como la aparición de una nueva cultura de las colonias. ${ }^{9}$ La formulación de reivindicaciones culturales, así como las relacionadas con los medios de comunicación por parte del CDP, es reciente; constituye un proyecto incipiente y para cuyo logro reconocen, de antemano, las graves dificultades que implica.

Este conjunto de demandas evidencia que el CDP combina las de carácter económico con las de tipo político. Por otra parte, destaca la inclusión de reivindicaciones de corte cultural o ideológico; el Comité ha sido uno de los primeros MUP del país en plantearlas.

\subsection{Organización}

El CDP constituye no sólo un frente con capacidad de movilización sino que posee también una estructura orgánica permanente. Ésta tiene como postulados básicos la participación directa de los colonos y la coordinación central de esta participación (CDP, 1982:4). Ambos se garantizan en la asamblea de cada colonia. En cuanto a las asambleas generales ordinarias, debido al número de integrantes de las diferentes colonias, eran normalmente tumultuosas y no facilitaban el análisis de los asuntos planteados. Por ello se han sustituido por el congreso de delegados (CDP, 1982a: 7) o asamblea de coordinadores que opera durante el lapso que transcurre entre un congreso y el siguiente. El congreso o asamblea plenaria de

${ }^{9}$ Comentario emitido en la entrevista a dirigentes. Véase también A. Meza, 1984: 94. 
todas las colonias y comités de colonias es la máxima instancia del CDP y tiene lugar una vez por año. Éste ha privilegiado la democracia de las bases, es decir, su intervención sistemática, evitando la dispersión organizativa y la descoordinación política, combinando así la participación amplia y directa con la centralización. Un principio básico del CDP es que la organización propia y autónoma de las colonias debe ser capaz de resolver las necesidades y contradicciones internas, así como autogestionar los servicios (educativos, médicos, etc.) de que ya dispone. Para alcanzar esto es fundamental contar con cuadros o activistas en cada colonia. Su formación se está logrando lentamente por medio de sesiones intensivas de entrenamiento y formación, que tienen lugar cada seis semanas; éstas constituyen las llamadas "escuelas del pueblo". A estas sesiones de estudio y análisis se suman las de planificación, para encontrar respuestas a las necesidades sentidas por las bases e insertarlas en los planes de acción.

En las entrevistas y visitas de campo realizadas se comprobó que la estructura organizativa formal que posee el CDP opera en los hechos; es decir, que la existencia de la dirección formal o Comisión Política no cancela las atribuciones y el margen de acción de las instancias restantes. Y el hecho de que el CDP posea una organización estable no anula la participación directa, la movilización de las bases, ni la fluidez entre éstas y la dirigencia. Ello ha permitido a este movimiento crear entre los colonos una organización dinámica y en proceso de consolidación.

\subsection{Formas de lucha}

Para la consecución de sus objetivos, el CDP utiliza recursos tanto legales como de hecho. El fundamental es la movilización mediante marchas, mítines, manifestaciones, paradas permanentes y plantones. A partir de ella establece negociaciones, presiona $y$, si los recursos legales no son suficientes, actúa mediante luchas extralegales, como tomas de edificios públicos, bloqueo de calles, etc. La tolerancia a este tipo de luchas por parte de las autoridades de la entidad se explica, en parte, por el descontento popular existente en la localidad y por la relativa reducción del margen de maniobra del partido oficial, ya aludidos.

De entre las formas de lucha utilizadas por el CDP destacan la organización de grupos de solicitantes de terrenos ante las autoridades y dependencias correspondientes (Indeco, Instituto de Vivienda del Estado, etc.) y la constitución de campamentos. Estos últimos implican la concentración de contingentes de solicitantes o colonos en los límites de los predios que desean obtener, sin ocuparlos en absoluto. Mediante esta táctica se hace pública su necesidad de tierra y el interés de negociar con el dueño de los rredio: su adquisición en condiciones favorables o de obtener la expropiación le los mismos.

El CDP recurr ? a la negociación con el Estado y sus dependencias cuan- 
do es factible y suficiente. Y para cubrir algún pago por concepto de introducción de servicios urbanos, incluyen en la negociación del mismo la consideración del trabajo realizado por los colonos, como una aportación económica real al proyecto correspondiente.

Las formas de lucha enunciadas corresponden a un grupo de presión que posee no sólo capacidad de movilización sino también habilidad para negociar. La combinación de ambos aspectos no es frecuente entre los MUP y el hecho de que el CDP lo haya conseguido indica los avances que está realizando. Esta fuerza del movimiento es reconocida por otras instancias sociales de la entidad; así, con motivo de la "consulta popular" realizada en Durango durante la última campaña presidencial, el secretario general de la sección XVI del Sindicato de Trabajadores del IMSS en el estado afirmó: "No nos conmueve ni nos preocupa la situación de los partidos de oposición. . . Sí nos preocupa. . . que se aumenta la actividad e importancia de grupos independientes. . . que no hemos sido capaces de sumar al nuestro (partido)" (IEPES, 1981:20). En el contexto de la intervención de este representante sindical era claro que se refería al CDP.

\subsection{Resultados y logros}

El grado de estructuración de un MUP está estrechamente relacionado con las conquistas que logra, tanto de tipo urbano como político e ideológico. En sus siete años de existencia, el CDP ha logrado dar cumplimiento a varias de sus demandas (CDP, 1982a:2).

En relación con suelo y vivienda destacan: a) la formación de varias colonias populares; b) el inicio del proceso de regularización de la tierra a muy bajo costo en cuatro colonias; c) la reducción, en $50 \%$, en el pago del impuesto predial para todas las colonias afiliadas al CDP, y d) la obtención de un crédito del Fondo Nacional de la Habitación Popular (Fonahpo) para adquirir un predio y construir viviendas.

En cuanto a servicios públicos sobresalen: a) la instalación de nuevas escuelas (jardines de niños, primarias y secundarias) en varias colonias, le ampliación de los planteles y el aumento de los profesores asignados en otras b) la reducción del impuesto municipal por concepto de limpia para to ras las colonias del Comité; c) la conservación de la cuota fija en el consumo de agua potable para las colonias hasta 1984; d) la autorización de un mercado manejado en forma cooperativa e independiente de la alcaldía, y e) la obtención del registro de la "Unión de Transportistas", articulada al CDP, para que opere en el municipio, a pesar de la fuerte oposición de la CTM local.

En el terreno político resaltan los avances internos logrados por el CDP tanto en la elevación de la conciencia de sus bases y en la formación de cuadros como en la estructuración del movimiento. Por ello, el logro más importante es la existencia misma de la organización. A esto debe agre- 
garse la utilización a su favor de las dificultades que registran el sistema y el partido oficial en la localidad y el apoyo logrado hacia sus causas entre partidos de izquierda, sindicatos y organizaciones populares tanto locales como externas a la ciudad y otras de carácter nacional.

En el campo de la cultura, el CDP ha puesto en operación desde 1984 el centro José Revueltas en una zona céntrica de la ciudad, complementado con subcentros o talleres en las colonias principales del Comité pará "difundir, rescatar y construir elementos de cultura popular alternativa".

A pesar de los logros enlistados, las características materiales de muchas de las viviendas en las colonias del CDP son deficientes y existen todavía carencias de servicios básicos, principalmente agua potable, drenaje, escuelas, consultorios y pavimentación en las calles. Esta situación es diferencial de acuerdo con el tiempo de creación de cada colonia y su grado de consolidación. ${ }^{10}$ En conjunto, predominan las colonias de reciente creación e incluso el movimiento está todavía ampliando sus bases en la ciudad. Por ello, si se compara esta situación con la prevaleciente en otros asentamientos de la propia ciudad o de otras del país y que se hallan incorporadas al PRI, no es desventajosa para el CDP. Como es sabido, después de 15 años o más de afiliación a la CNOP existen colonias que carecen de los servicios más fundamentales.

En cuanto al nivel de participación de las bases en las diferentes actividades acordadas, éste es desigual y el avance en las demandas culturales, lento. Pero los resultados parciales obtenidos señalan que, a través de una organización independiente está siendo posible mejorar las condiciones de hábitat y elevar paulatinamente la conciencia política e ideológica de los integrantes de los movimientos.

\subsection{El CDP, las fuerzas sociales de la localidad y la respuesta del Estado}

Los logros obtenidos por el CDP obedecen básicamente a la influencia que este frente ha logrado ejercer en las colonias populares de la ciudad y en su organización autónoma. De un total aproximado de 60 colonias, la CNOP controla alrededor de 20, existiendo un número similar en una situación de indefinición política, mientras que el CDP aglutina a otras 20 , y está aumentando sus bases en la localidad. ${ }^{11}$ Por ello los poderes de la enti-

${ }^{10}$ En el momento de la visita de campo (octubre de 1982), las colonias de más reciente creación (Genaro Vázquez, Arturo Gamiz y Tierra y Libertad) carecían de agua potable en las viviendas y de drenaje. La colonia Emiliano Zapata contaba con suficientes aulas y, mientras la SEP no las instala en las restantes, las colonias construyen o adaptan locales para este fin. Excepto la colonia Lucio Cabañas, las demás carecían de consultorios, y las calles de todas las colonias no contaban con pavimentación.

${ }^{11}$ Dato obtenido a través de las entrevistas, visitas de campo y de A. Meza, 1984: 91. 
dad desean frenar esta fuerza social que no está siendo controlada por ellos.

De hecho, el Comité se ha constituido en una de las fuerzas políticas locales importantes. Esta situación no ha sido aceptada por los grupos de poder de la entidad, principalmente la seccional de la Cámara Nacional de Comercio (Canaco) ni por sus aliados (la burocracia política, el alto clero católico, los partidos de derecha) y las capas medias. Asimismo, el gobernador intentó, por varios medios, revertir este proceso de acumulación de fuerzas por parte del CDP. Con este fin trató de infiltrar el movimiento, recurrió a campañas de desprestigio a través de los medios de comunicación locales y, en varias ocasiones, desalojó a los colonos y reprimió a sus dirigentes. La utilización de estos recursos demuestra que los poderes de la entidad están limitando la función de interlocutor y mediador que el CDP tiene derecho a ejercer como parte organizada de la sociedad civil. Por contrapartida, a la luz de estas prácticas cobran mayor sentido e importancia los logros que, pese a ello, ha obtenido el CDP.

La respuesta de los poderes locales al Comité está directamente relacionada con la política semicorporativa del Estado mexicano. Éste, como es sabido, ha demostrado desde el periodo cardenista, gran capacidad para integrar los diferentes grupos sociales e incorporarlos a su proyecto político. Por ello y a pesar de su carácter emergente, la existencia de movimientos que desbordan los límites institucionales y las normas establecidas para el planteamiento de demandas afecta a uno de los elementos básicos de sustentación del sistema. Ello explica la aguda sensibilidad que el Estado manifiesta hacia las expresiones de vida orgánica independiente, sobre todo si se agregan a otros factores que indican la reducción reldtiva del poder del sistema a nivel local.

En cuanto al CDP, los datos presentados manifiestan que si bien su origen y evolución están relacionados con medidas (fiscales, urbanas, etc.) adoptadas por el Estado, la dinámica del movimiento obedece, en buena parte, a su propia vida orgánica y política.

\subsection{Solidaridad, alianzas y relaciones orgánicas}

El CDP ha brindado solidaridad a otras colonias y organizaciones populares de la propia capital del estado (Frente Popular Independiente de Fincas Urbanas) o del interior del mismo (Frente Obrero Campesino Estudiantil de Gómez Palacio) o ajenas a él (FT y L de Monterrey, León y D.F., principalmente). Asimismo ha prestado apoyo a obreros en huelga como los de la fábrica de triplay y los mineros de la empresa Nombre de Dios; igualmente ha apoyado las luchas de los estudiantes y campesinos. En general, estas relaciones han sido puntuales, pero tienden a estabilizarse por medio de las delegaciones en la entidad del Frente Nacional en Defensa del Salario y Contra la Austeridad y Carestía (FNDSCAC) y la Asamblea Nacional Obrera, Campesina y Popular (ANOCP). 
El Comité ha creado también nexos con otras fuerzas sociales de la entidad o del país; así, por ejemplo, ha establecido alianzas, a nivel estatal, con los sindicatos de trabajadores universitarios, con organizaciones estudiantiles y feministas, y con las secciones locales de grupos políticos y organizaciones de izquierda.

Respecto a las relaciones orgánicas del Comité debe subrayarse el papel que desempeñó la constitución de la Conamup. A escasos meses de su propia creación, el CDP fue promotor junto con el FPT y L de Monterrey, la Unión de Colonias Populares (UCP) del valle de México y el Comité de Defensa Popular (CDP) de Zacatecas del "Primer Encuentro Nacional de Movimientos Populares"' que tuvo lugar en mayo de 1980 en Monterrey. Como es sabido, este encuentro fue el antecedente inmediato del que surgió la Coordinadora del Movimiento Urbano Popular. A pesar de sus limitaciones orgánicas y políticas, la Conamup representa un avance notable en la vida de los MUP, puesto que ante la dispersión que sufrían, la creación de este frente amplio significa su progresiva unificación y la búsqueda de un programa y plan de acción comunes a nivel tanto nacional y regional como local. Y el papel que el CDP ha desempeñado es el de pionero y gestor en este proceso de unidad y articulación orgánica del MUP.

El papel que el Comité representó en la creación de la Conamup no se redujo a su constitución; el CDP es uno de los puntos de apoyo de esta coordinadora. Su presencia y participación en las reuniones, asambleas, encuentros y actividades programadas por este frente sectorial son constantes. Por otra parte, fue el anfitrión y organizador del "Segundo Encuentro Nacional de Movimientos Populares" celebrado en abril de 1981, en el que la Conamup adquirió carácter permanente. Esta misma colonia fue, en noviembre de 1983, la sede del "Primer Encuentro Nacional de Mujeres del Movimiento Popular". Estos datos evidencian la importancia que el CDP asigna a la solidaridad y alianzas y, asimismo la función aglutinante que está desempeñando el Comité al interior del movimiento urbano popular.

\subsection{EI CDP y la lucha electoral}

Frente al bajo nivel de conciencia que se asigna a los MUP y a la "marginalidad" política de que supuestamente adolecen, debe resaltarse la evolución que las posiciones del CDP han tenido en materia electoral. En el segundo encuentro nacional de la Conamup, mantuvo con firmeza que la Coordinadora, como tal, no debía participar en las elecciones y que era decisión de cada organización integrante asumir la postura que considerara más adecuada con tal de que favoreciera el avance independiente del MUP. Por su parte, además de abstenerse de votar en las elecciones presidenciales de 1982, realizó una campaña para que la ciudadanía de Duran- 
go no participara en este proceso electoral. La autocrítica que el propio Comité realizó a esta medida la resume en estos términos: "Esta lucha nos redituó un profundo aislamiento social. Numerosas campañas de desprestigio se desataron en contra nuestra. Llamamos la atención del gobierno federal y así facilitamos la represión policiaca contra nuestros dirigentes, y las demandas concretas que pretendíamos negociar con esta lucha no obtuvieron respuesta" (UCP, 1982a: 3 y 4). Como resultado de esta autocrítica, el CDP reajustó sus posiciones. En las elecciones municipales de 1983 y de diputados federales de 1985 no se pronunció sobre estos procesos y remitió a sus miembros la libre decisión a este respecto. Y en las correspondientes a la elección de gobernador, alcaldes y diputados de 1986, estableció una alianza en la que los candidatos del Comité participaron bajo el registro legal del PRT. A través de este recurso, el CDP intenta utilizar las elecciones como medio de defensa y asimismo para abrir nuevos espacios políticos en la localidad.

Estos cambios del Comité sobre el ejercicio de uno de los derechos políticos fundamentales demuestran que no concibe su existencia y actividad como un elemento marginal a la vida política general y de la localidad en particular. Por el contrario, quiere ser reconocido como parte organizada de la sociedad civil y participar electoralmente. Ello implica un avance y maduración respecto a sus posiciones iniciales. En esta evaluación han influido tanto el proceso de consolidación interna del Comité como su experiencia negativa con el PAN, mientras este partido detentó la alcaldía del municipio de Durango (Pizarro, 1983: 20).

\section{Conclusiones}

En México, la posibilidad de mejorar las condiciones materiales de vida de las mayorías urbanas ha sido asociada, en los estudios de las reivindicaciones urbanas, a la presencia del PRI en las colonias populares y a la supeditación de éstas al sistema. Sin embargo, el anális del CDP manifiesta que esta doble relación no es constante ni necesaria. Relacionando las características de este movimiento con las hipótesis formuladas sobre él, se evidencia que:

1. El "movimiento urbano popular" en Durango tiene lugar en una ciudad de carácter medio que posee un bajo índice de industrialización y cuyo desarrollo urbano no manifiesta niveles superiores al promedio nacional. Asimismo, las condiciones materiales de vida de las mayorías de esta localidad no acusan niveles de deterioro superiores al del resto de las ciudades del país. El caso estudiado demuestra que la situación política local y el nivel de conciencia y organización del movimiento adquieren importancia decisiva como variables explicativas del fenómeno estudiado. 
2. El CDP plantea demandas no sólo económicas sino también políticas e ideológicas, manifestando avances en la conciencia de sus integrantes y en la consolidación del movimiento. Por otra parte, la existencia del Comité no es el resultado de una respuesta espontánea ni masiva a conflictos puntuales sino (a partir de experiencias de lucha locales) la cristalización de un trabajo prolongado de concientización y organización de las bases que, de manera relativamente lenta, se fueron incorporando a este frente de lucha, que ha logrado continuidad a pesar de los intentos de desarticulación realizados contra él. Ello prueba que, en la medida en que se reúnen las condiciones anteriores, pueden generarse MUP que desborden los mecanismos de subordinación política e ideológica de que dispone el sistema de dominación. Además, el CDP ha desarrollado una importante labor de solidaridad y alianza con otras fuerzas sociales independientes de la localidad y ha impulsado la unificación de las fuerzas urbanas populares independientes del país a través de la Conamup, apoyando también su vinculación con otros sectores independientes. Hay, pues, una proyección política real en la actuación de este movimiento.

3. A nivel de la ciudad de Durango, el CDP no significa una organización minoritaria sino que nuclea contingentes similares o incluso mayores que los que integra corporativamente la CNOP en las colonias de la localidad. En este contexto, ello la convierte en una de las fuerzas sociales y políticas importantes. Si bien esta situación es relativamente excepcional en relación con otras ciudades y MUP del país, esto prueba que la hegemonía mantenida por el Estado en este terreno es modificable.

4. La creación del CDP está relacionada ciertamente con la política económica y urbana de los poderes locales y con sus intervenciones en las colonias populares, pero asimismo la evolución y consolidación del Comité se fundamentan en su propia dinámica e iniciativas. Por ello, dichos poderes están tratando de frenar el papel social y político que este movimiento desempeña como representante y mediador de núcleos crecientes de colonos en la ciudad de Durango.

Las conclusiones anteriores permiten afirmar que el CDP constituye, por el momento, uno de los MUP más estructurados en México. Ciertamente, como estudio de caso, los alcances del fenómeno son limitados y no extrapolables a otros movimientos urbanos; sin embargo, demuestran que los MUP están avanzando tanto en su organización interna como en su madurez política. En esta medida constituyen un fenómeno social cuya presencia no se puede ignorar y, por sí mismos, prueban que las luchas de las mayorías por demandas urbanas no necesariamente deben realizarse por medio de una relación de cliente con el Estado. 


\section{Bibliografía}

Alvarado, L. (1981), “Notas sobre las perspectivas teóricas en el análisis de las luchas reivindicativas urbanas", en Revista Mexicana de Sociología, vol. XLIII, núm. 4, 1395-1413.

Borja, J. (1975), Movimientos sociales urbanos, Ediciones SIAP-Planteos, Buenos Aires.

Borrego, R. (1984), “Una aproximación al estudio del movimiento estudiantil de 1966 en Durango", mimeo., 28 pp.

Casanova, Pablo, Samuel León e Ignacio Marván, coords. (1984), El obrero mexicano (5 volúmenes), Siglo XXI, México.

Castells, Manuel (1974), Movimientos sociales urbanos, Siglo XXI, Madrid. (1981), Capital multinacional, estados nacionales, comunidades locales, Siglo XXI, México.

Centro Operacional de Vivienda y Poblamiento (1977), El capital en la producción de vivienda, Copevi, México.

Comité de Defensa Popular de Durango (1981), “Organicémonos y luchemos contra los explotadores del pueblo", mimeo.

(1982a), "Balance anual del movimiento popular en Durango, septiembre, 1982", mimeo. (1982b), "Proyecto organizativo", mimeo.

Cornelius, W.A. (1974), "Urbanization and Political Demand Making: Political Participation among the Migrant Poor in Latin Américan Cities", en American Political Science Review, vol. LXVIII, núm. 3, 1125-1146. (1980), Los emigrantes pobres en la ciudad de México y la política, FCE, México.

Escudero G.A. (1984), “El movimiento urbano popular en la ciudad de Durango a partir de 1970", mimeo., 10 pp.

Hardy, C. (1985), "Caracterización de la marginalidad popular: escenario constitutivo de nuevos actores", en Investigación económica, 174, 161-181.

IEPES (1981), Estado de Durango. Consulta Popular Durango, IEPES, México.

Infonavit (1981), "Indicadores de la necesidad y demanda de vivienda urbana", Infonavit, México.

Melucci, A. (1976), Movimenti di rivolta. Teorie e forme dell'azione collettiva, Etas Libri, Milán. (1982), Sistema político, Partiti e movimenti sociali, Giangiacomo Feltrinelli Editore, Milán. (1984) Altri codici. Aree di movimento nella metropoli, Societá editrici Il Mulino, Bolonia.

Mercado, A. (1983), “Crisis económica y despliegue del movimiento urbano y popular en México”, en Testimonios, 1, 37-57.

Moctezuma, P. (1981), "Las luchas urbano-populares en la coyuntura actual", en Teoría y Política, núm. 5, 101-124.

Meza, Armando (1984), "El movimiento urbano popular en Durango", en Nueva Antropología, núm. 24, 89-98.

Ornelas, N.C. (1984), “Durango 70”, mimeo., 29 pp.

Peattie, L. (1979), “La organización de los marginales", en R. Katzman y J.L. Reyna, Fuerza de trabajo y movimientos laborales en América Latina, El Colegio de México, México.

Pizarro Ch., F.J. (1984), "Las elecciones locales de 1983 en Durango" mimeo., 21 pp.

Pradilla, Emilio (s/f), "La lucha de clases y la cuestión urbana. Acerca de los llamados movimientos sociales urbanos"', mimeo.

Presidencia de la República (1983), “Participación democrática, Durango' , México, núm. 30. 
PSUM (1982), "Política urbana del PSUM y programa de demandas alternativas", mimeo.

Ramírez, Juan Manuel (1983), Carácter y contradicciones de la Ley General de Asentamientos Humanos, UNAM, México.

(1986), "La Conamup y la política", en El Cotidiano, núm. 11, 26-33.

(s/f), El movimiento urbano popular en México, Siglo XXI, México, en prensa. (s/f) Política urbana y lucha popular, UAM-X., México, en prensa.

SAHOP (1979a), Plan Municipal de Desarrollo Urbano de Durango, México. (1979b), Programa Sectorial Estatal de Vivienda para el Estado de Durango, México.

(1982) “Escoplan del municipio de Durango", México.

Sánchez-León, Abelardo (1983), "Relación entre planificadores y organizaciones sociales de pobladores en áreas urbano-populares, en Revista Interamericana de Planificación, núm. 67, 54-63.

Topalov, Christian (1975), Los agentes urbanos y la producción de vivienda, Documents d'Analisis Urbana, núm. 3, Publicaciones del Departamento de Geografía de la Universidad Autónoma de Barcelona, Bellaterra.

Topalov, Christian (1979), La urbanización capitalista, Ed. Edicol, México.

Zapata, Francisco (1985), "Lucha nacional y movimientos sociales", en Diálogos, núm. 123, 10-15. 